\title{
Research on Power Enterprise Supplier Management System Based on Supplier Deep Portrait
}

\author{
Mengru Shen*1,a, Xiaoran Pang, ${ }^{2, b}$, Tong Chen ${ }^{3, c}$, Lei Tang, ${ }^{4, d}$ Hui Wan ${ }^{5, \mathrm{e}}$ \\ ${ }^{1}$ Key Laboratory of Transport Industry of Big Data Application Technologies for Comprehensive Transport, Beijing Jiaotong University \\ Beijing, China \\ ${ }^{2}$ College of Transportation, Beijing Jiaotong University Beijing, China \\ ${ }^{3}$ College of Transportation, Beijing Jiaotong University Beijing, China \\ ${ }^{4}$ College of Transportation, Beijing Jiaotong University Beijing, China \\ ${ }^{5}$ College of Transportation, Beijing Jiaotong University Beijing, China
}

\begin{abstract}
In current supplier management business status of power enterprises, exists many common pain points, such as weak supplier data management, weak risk management awareness. With the intention of solving these problems, this research proposes a deep portrait system of suppliers of power enterprises by constructing full information database of suppliers, establishing a comprehensive evaluation index system of suppliers, and building a supplier label library. With the application of this system, this paper designs the business mechanism optimization scheme of the whole life cycle auxiliary management, which includes supplier qualification and performance verification, professional performance evaluation, market performance insight and risk control. This system proposed is of great significance to improve the lean level and informatization process of supplier management in power enterprises.
\end{abstract}

\section{Introduction}

The suppliers of power enterprises are numerous and diverse, and the supplier management ability of power enterprises is closely related to the security and reliability of power grid. At present, there are many problems in the extensive supplier management of power enterprises, which have caused a lot of troubles and consumed a lot of manpower and material resources in subsequent electric power network operation and bidding work. The specific problems are as follows: (1) Data distribution trivializes situated, the data integration between systems is low, and the unstructured is serious. (2) Supplier evaluation is a mere formality with low intelligence, and the dynamic control of supplier professional performance is not realized. (3) Awareness of suppliers risk management is too weak, and market trend monitoring mechanism hasn't been established yet.

Domestic and foreign scholars have explored some solutions for these problems. Li Ming designed a main data management system for customers and suppliers of Masteel Group ${ }^{1}$. Yang Xinyi et al. developed a scientific and reasonable index scoring system for power grid enterprises by rearranging and optimizing key indicators, setting indicators differently, increasing the proportion of quantitative indicators, and optimizing the index weight ${ }^{2}$. Lu Jing discussed the possible risks in the process of supplier selection, product design and development, and management, and proposed to prevent and control the potential risks of suppliers from the ownership structure, financial status, sample testing, factory conditions, production process monitoring and other aspects ${ }^{3}$. Bai Xufei integrated the information of various material suppliers, constructed the knowledge map of power grid suppliers, proposed the automatic evaluation and labeling of suppliers with artificial intelligence natural language technology to construct the 360-degree holographic picture of labeled suppliers, and built the business scenario application of full-chain optimization and link optimization in stages ${ }^{4}$.

Based on the above research ideas and methods, this research constructed the supplier deep portrait system, by putting forward the supplier data integration and unified management, establishing a comprehensive evaluation index system of suppliers' qualification, manufacturing, supply, installation service and operation service ability; and putting forward the principles and ideas of building supplier label library. Put forward the whole link and intelligent solution for the supplier management system of power enterprises and carry out innovative optimization.

\section{Construction of Supplier Deep Portrait System}

\subsection{Construction of Supplier Full Information Database}

The traditional supplier management business isolates the information systems such as ECP, ERP, economic and legal business system from each other, lacks unified

a*mrshen@bjtu.edu.cn, b20120987@bjtu.edu.cn

c18251238@bjtu.edu.cn, ${ }^{\mathrm{d} 18271077 @ b j t u . e d u . c n,{ }^{\mathrm{e}} 18251072 @ b j t u . e d u . c n}$ 
supplier data management, and haven't realized a complete coverage of supplier information in all business links. For instance, the suppliers who didn't have cooperation experience lack of historical data in the systems, which causes the risk of blank data to judge the performance ability and the quality risk, a lot of uncertainty in supplier qualification and performance verification, comprehensive evaluation and selection, and higher risk in material bidding procurement and project construction. Therefore, it is necessary to establish a supplier full information database. According to the business demands of each link in supplier management practice, realize the dynamic update of the supplier full information, and provide data support for the supplier deep portrait system.

The supplier full information database can be divided into data acquisition layer, data storage layer, data application layer and data access layer. And its architecture is shown in Figure 1.

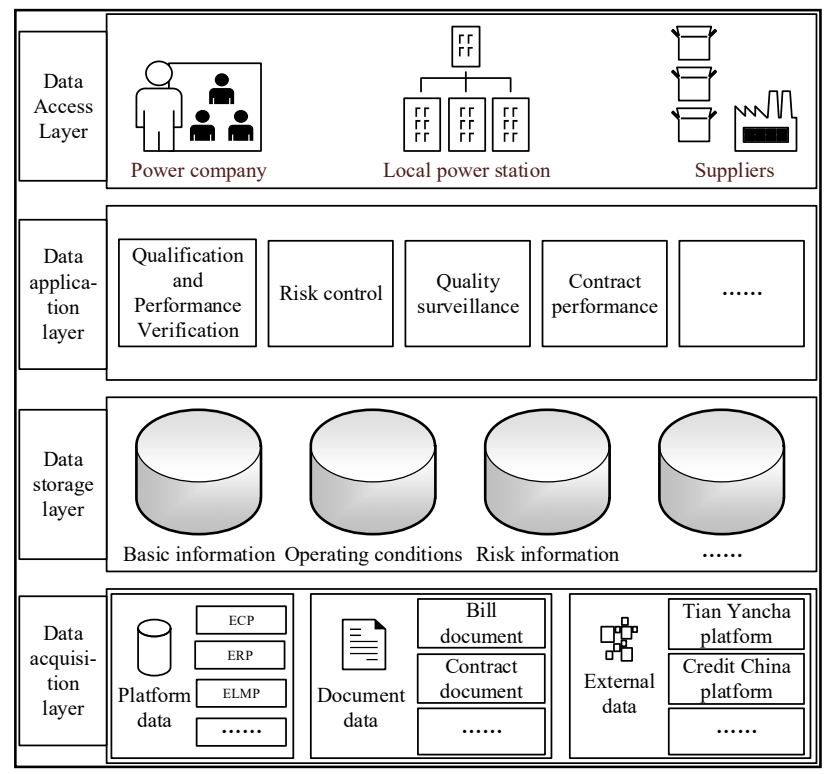

Figure 1 The architecture of the supplier full information database

The data acquisition layer is the base of the database. This layer relies on the business modules of bidding, procurement and project construction of internal ECP, ERP and other information systems to collect relevant information that can represent the professional performance of suppliers. Collect documents data of bill documents and contract documents inside the enterprise through file uploading module; Obtain credit, risk and other information from external credit investigation agencies such as Credit China or enterprise information open platforms such as Tianyancha. Through the design of ETL and enterprise information integration module, integrate comprehensive data of enterprise internal and external.

The data storage layer realizes the structured storage of the supplier full information by structuring the data storage units such as basic information, operation status and risk information of suppliers, and constructing databases in different themes.
The data application layer provides data support for relevant businesses by calling business model interfaces such as supplier qualification and performance verification, risk control and quality supervision.

According to the different roles of user, the data access layer design specific permissions. For the power enterprises' different departments, local power station and suppliers, open the corresponding data access, and provide access tools such as ad-hoc query, data mining, to enable users obtain multidimensional display of data such as visual charts and data analysis reports, thus, and obtain auxiliary support of decision-making, analysis and management.

\subsection{Establishment of supplier comprehensive evaluation index system}

Based on the supplier full information database, establish the supplier comprehensive evaluation index system. The supplier comprehensive evaluation model is the basis of the application of supplier deep portrait, and the supplier comprehensive evaluation index is the quantitative means to construct the supplier label. Add the external credit, public praise and other indicators to the existing mainstream power enterprise supplier evaluation index system $^{2}$, and make weighted scores, so as to form a comprehensive index score value. This research uses AHP to design the weight of evaluation index and optimize it according to the existing situation ${ }^{5}$.

At present, the existing professional performance evaluation system of power enterprise suppliers mainly divides suppliers into two categories: material suppliers and service suppliers. Taking the production material suppliers as an example, based on a large number of researches and expert interview results of material department of electric power enterprises, this research comprehensively evaluates the production material suppliers from five aspects: qualification ability, manufacturing, material supply, installation service and operation service ability. Under each index, it is divided into multiple secondary indexes, which are divided into third indexes, and the corresponding weights are allocated according to the actual business needs and expert opinions to realize the integrity and structure of the index system.

Table1. evaluation system of production materials Suppliers

\begin{tabular}{|c|c|c|}
\hline $\begin{array}{c}\text { First Grade } \\
\text { Indexes }\end{array}$ & $\begin{array}{c}\text { Second Grade } \\
\text { Index }\end{array}$ & Third Grade Index \\
\hline \multirow{8}{*}{$\begin{array}{l}\text { Qualification } \\
\text { assessment (20\%) }\end{array}$} & \multirow{3}{*}{$\begin{array}{l}\text { Company scale } \\
(20 \%)\end{array}$} & Company area $(30 \%)$ \\
\hline & & $\begin{array}{l}\text { Total number of employees } \\
(30 \%)\end{array}$ \\
\hline & & Annual revenue $(40 \%)$ \\
\hline & \multirow{3}{*}{$\begin{array}{l}\text { Production capacity } \\
(40 \%)\end{array}$} & $\begin{array}{l}\text { Research and development } \\
\text { level }(30 \%)\end{array}$ \\
\hline & & $\begin{array}{l}\text { Production equipment level } \\
(50 \%)\end{array}$ \\
\hline & & $\begin{array}{l}\text { Production area manpower } \\
(20 \%)\end{array}$ \\
\hline & \multirow{2}{*}{$\begin{array}{l}\text { Credit and } \\
\text { reputation }(40 \%)\end{array}$} & Dishonest conduct $(20 \%)$ \\
\hline & & Social recognition $(20 \%)$ \\
\hline
\end{tabular}




\begin{tabular}{|c|c|c|}
\hline & & $\begin{array}{l}\text { Peer company evaluation } \\
(60 \%)\end{array}$ \\
\hline \multirow{4}{*}{$\begin{array}{l}\text { Manufacturing } \\
\text { capacity }(25 \%)\end{array}$} & \multirow{2}{*}{$\begin{array}{l}\text { Production level } \\
(60 \%)\end{array}$} & Production rate $(40 \%)$ \\
\hline & & Product quality $(60 \%)$ \\
\hline & \multirow{2}{*}{$\begin{array}{l}\text { Equipment } \\
\text { supervision } \\
(40 \%)\end{array}$} & $\begin{array}{l}\text { Pass rate of factory experiment } \\
(30 \%)\end{array}$ \\
\hline & & \begin{tabular}{|l|} 
Supervision and inspection \\
cooperation \\
degree $(70 \%)$ \\
\end{tabular} \\
\hline \multirow{5}{*}{$\begin{array}{l}\text { Material supply } \\
\text { capacity }(20 \%)\end{array}$} & \multirow{3}{*}{$\begin{array}{l}\text { Supply ability } \\
(50 \%)\end{array}$} & Supply service level (40\%) \\
\hline & & Prompt delivery $(30 \%)$ \\
\hline & & Qualification of supply (30\%) \\
\hline & \multirow{2}{*}{\begin{tabular}{|l} 
Contract \\
performance (50\%)
\end{tabular}} & $\begin{array}{l}\text { Contract signing cooperation } \\
(35 \%)\end{array}$ \\
\hline & & $\begin{array}{l}\text { Contract change feedback } \\
\text { timeliness }(65 \%) \\
\end{array}$ \\
\hline \multirow{4}{*}{$\begin{array}{l}\text { Installation service } \\
\text { capability }(20 \%)\end{array}$} & \multirow{2}{*}{$\begin{array}{l}\text { Service performance } \\
(55 \%)\end{array}$} & Timeliness of service $(50 \%)$ \\
\hline & & Service quality $(50 \%)$ \\
\hline & \multirow{2}{*}{$\begin{array}{l}\text { Commissioning } \\
\text { inspection }(45 \%)\end{array}$} & Qualified acceptance (65\%) \\
\hline & & Legacy defect (35\%) \\
\hline \multirow{4}{*}{$\begin{array}{l}\text { Operation service } \\
\text { capability }(15 \%)\end{array}$} & \multirow{2}{*}{$\begin{array}{l}\text { After-sale service } \\
(55 \%)\end{array}$} & after-sale service (30\%) \\
\hline & & Problem solving ability $(70 \%)$ \\
\hline & \multirow{2}{*}{$\begin{array}{l}\text { Technical support } \\
(45 \%)\end{array}$} & $\begin{array}{l}\text { Technical support timeliness } \\
(50 \%)\end{array}$ \\
\hline & & $\begin{array}{l}\text { Technical support quality } \\
(50 \%)\end{array}$ \\
\hline
\end{tabular}

\subsection{Supplier label library construction}

The supplier label library is the core of the supplier deep portrait system. On the basis of the supplier full information database, design the tag library that can comprehensively reflect the behavior and performance of suppliers according to the evaluation dimensions set by the supplier comprehensive evaluation index system. Through the label attribute design of different dimensions, explore the methods of the supplier classification management to realize refined supplier management and accurately obtain the market dynamics of power materials. Through the design of algorithms and models and introduction of data mining rules, strengthen the data analysis level of power enterprises, fully release the commercial value of massive supplier data, and help power enterprises operate more efficiently.

According to different ways of obtaining label information, labels can be divided into statistical, computing class and predion class labels, as shown in Figure 2.

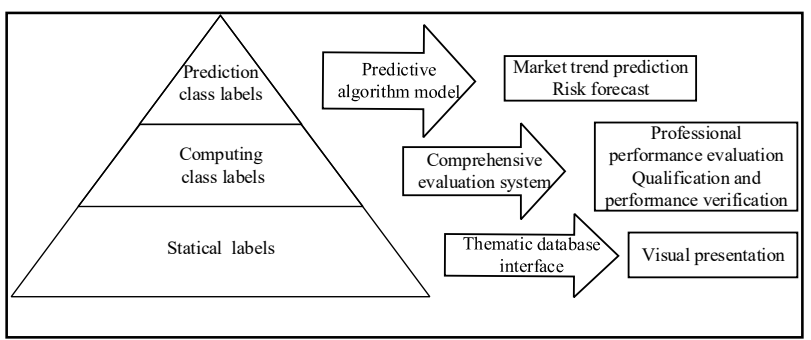

Figure 2 Label types and their applications
The statistical labels reflect the facts of the supplier, which are the most basic labels. Through the design of data interface, the information can be obtained directly from the thematic database of supplier basic information. Statistical labels can be visually presented directly to help decision-making departments intuitively learn of the basic information and status of suppliers. These labels are: business license, financial report, enterprise scale, etc.

The computing class labels are based on the statistical labels and the supplier comprehensive evaluation index system, are obtained by calculating the supplier' s qualification ability, contract performance and other behavioral assessment. These labels are: market share, ownership structure, concentration. Computational labels can provide direct data support for qualification and performance verification and professional performance evaluation business.

The prediction class labels reflect suppliers' risks and market performance trends. Design prediction models to fit possible trend information and carry out iterative training continuously to improve the prediction accuracy of the models. These labels are: profit trend, enterprise risk level forecast, industry development trend, industry profit trend. Through the acquisition of predictive label information, conduct supplier market trend prediction and risk prealarm.

In addition to label creation and class design, the label system should be maintained continuously, and the label library should be updated iteratively based on the occurred problems in the application of the label library and the newly discovered business requirements.

\section{Application scheme}

Based on the supplier deep portrait system, this research designed the optimization scheme of supplier full life cycle management business mechanism, which covers five stages: bidding, contract signing, contract performance, contract settlement and re-cooperation.

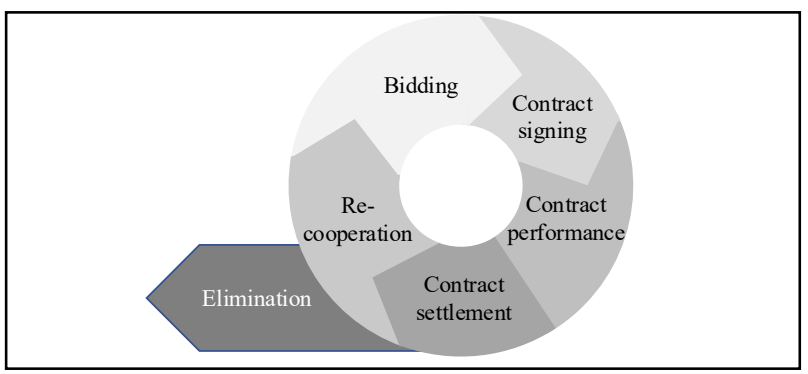

Figure 3 Supplier full life cycle

In the bidding stage, optimize the supplier qualification and performance verification business mechanism.

The supplier deep portrait system designs structured processing modules for the supplier's enterprise scale, supply performance and other qualification and performance data, so as to realize the highly structured collection of supplier information. Among the data required for this business, suppliers' basic information, performance and capability and other general data can be automatically obtained from the supplier full information 
database, and automatically form a qualification and performance verification table, which enhances the level of business intelligence. Establish a sound and complete correlation mechanism to integrate contract ledger sheets and historical projects' information and orders' information, regularly update to synchronize new performance information, eliminate the original data, and dynamically update the contract ledger sheet, so as to achieve the purpose of real-time and accurate update of performance data.

In the contract performance stage, optimize the professional evaluation mechanism of supplier performance.

The supplier full information database system tracks the whole process of the contract, supervises and urges the business personnel in the application layer to score in time, evaluates the professional performance of different material category suppliers through the supplier comprehensive evaluation index system, and realizes the dynamic update of the supplier evaluation results, thus providing accurate and comprehensive strong support for the bidding and procurement work.

Insight into the market performance of suppliers and eliminate unqualified suppliers during the cooperation process. Accurately grasp suppliers' internal and external market performance ability from overall and individual perspective based on the supplier deep portrait system. According to the material category provided, construct the supplier group portrait, which multidimensionally displays the quantity, evaluation scores of each index, rankings and comprehensive evaluation results of the same category suppliers. Thus, quickly identify the overall situation of this category supplier group. Through multidimensional display of supplier individual portrait, it can be quickly reviewed that the supplier's operating conditions and historical performance, so as to evaluate the performance and industrial competitiveness of the supplier in power enterprises, and quickly find out the advantages and disadvantages of the supplier compared with its competitors in the same material category. Thus, achieve accurate control of supplier market performance.

In the whole life cycle, based on the characterization of suppliers' risk indicators, carry out risk assessment of suppliers' credit, justice, operation and performance from multiple factual dimensions such as enterprise credit, legal litigation, executed person, dishonesty and administrative punishment. By quantitatively measuring the risk coefficient of the efficiency loss, personnel safety loss, social image loss and economic loss caused or possibly caused by the supplier, evaluate the risk level of the supplier, and form a supplier risk analysis report. By excavating suppliers' potential risks, prevent the dishonest or high-risk suppliers from winning the bid, to provide basis for effectively avoiding the risk of bidding and procurement and reduce the risk cost of bidding failure and procurement cost, thus, ensure the safe and stable operation of the power grid. In the full life cycle, based on the representation of each risk index of suppliers, risk assessment of suppliers' credit, justice, operation and contract performance is carried out from multiple factual dimensions, such as enterprise credit investigation, legal proceedings, persons subjected to enforcement, trust- breaking and administrative punishment. Through to the supplier has caused or may cause the efficiency loss, loss of personnel safety and the social image of measuring risk coefficient, loss and economic loss evaluation of suppliers to the risk level of the enterprise, the formation of risk analysis, mining potential risk, suppliers can avoid low performance score against dishonest suppliers and suppliers bid, provide the basis for effective avoid bidding and procurement risk, lowering the cost of bidding failure risk and purchasing cost, guarantee the safe and stable operation of power grid.

\section{4 conclusion}

This research constructs the supplier full information database, the supplier comprehensive evaluation index system, and the supplier label library, which constitute the deep portrait system of electric power enterprises' suppliers. And it designs business mechanism optimization schemes of supplier full life cycle management, including the supplier qualification and performance verification, professional performance evaluation, market insight, risk control. This research expands the supplier portrait application scenario and provide a new methodology to solve the problems existing in supplier management of power enterprises. It is of great significance to improve the lean level and informatization process of supplier management in power enterprises.

\section{Acknowledgment}

This research was funding from the Fundamental Research Funds for the Central Universities 2020JBM028 and the major scientific and technological innovation project of Shandong Province (No. 2019JZZY020715).

\section{References}

1. Li Ming, "Design of main data management system for customer and supplier of Masteel Group," Metallurgical Power, vol. 1, pp. 68-70, January 2020., in press.

2. Yang Xinyi, Yuan Yiwen, Cui Xiwen, Xu Tiantian, Zheng Sijia, Luo Jia and Wu Bo, "Construction and optimization of supplier differentiation performance evaluation system," Science Technology and Industry, vol. 21, pp. 169-173, February 2021., in press.

3. Lu Jing, "Research on the Potential Risks and Prevention of Supplier Management," Fujian Quality Management, vol. 17, pp. 21, September 2020., in press.

4. Bai Xufei, Xian Jiangnan, Shan Qiang and Sun Yuan, "Supplier 360-degree holographic image scene application based on knowledge map," Electronic Technology and Software Engineering, vol. 16, pp. 184-186, August 2020., in press.

5. Xu Kun, He Yumin, Lu Zhenyu, "Supplier quality performance evaluation," Modern business, vol.15, pp. 45-46, May 2020., in press. 